\title{
PANDEMIA, CRISE DE CUIDADOS E EDUCAÇÃO AMBIENTAL: O QUE APRENDER COM QUEM CUIDA DA VIDA?
}

\author{
Carolina Alves de Oliveira ${ }^{\mathrm{i}}$ \\ Léa Tiriba ${ }^{\text {ii }}$
}

\begin{abstract}
Resumo: Escrito no contexto da pandemia do Covid - 19, este texto traz reflexões sobre o cuidado como fenômeno que é a base possibilitadora da existência humana. Com base em levantamento bibliográfico, associado à análise de fatos desvelados pela crise pandêmica no Brasil, apresentamos três perspectivas para a educação ambiental: o cuidado como questão de gênero no contexto do capitalismo patriarcal; o rompimento das redes ambientais de cuidados nos territórios; e a crítica ecofeminista ao capitalismo, modelo de desenvolvimento que não cuida. Permeada pela noção de interdependência, a articulação entre estas três perspectivas nos permite concluir que a valorização das mulheres e da esfera da reprodução da vida, assim como das comunidades tradicionais e de seus saberes ancestrais são questões/desafios essenciais para a educação ambiental.
\end{abstract}

Palavras-chave: Pandemia; Cuidado; Ecofeminismo; Educação ambiental.

\section{PANDEMIA, CRISIS DE CUIDADOS Y EDUCACIÓN AMBIENTAL: QUÉ APRENDER CON QUIEN CUIDA DE LA VIDA?}

\begin{abstract}
Resumen: Escrito en el contexto de la pandemia de Covid-19, este texto trae reflexiones sobre el cuidado como un fenómeno que es la base habilitadora de la existencia humana. A partir de un levantamiento bibliográfico, asociado al análisis de los hechos revelados por la crisis pandémica en Brasil, presentamos tres perspectivas para la educación ambiental: el cuidado como cuestión de género en el contexto del capitalismo patriarcal; la ruptura de las redes de cuidado ambiental en los territorios; y la crítica ecofeminista del capitalismo, un modelo de desarrollo que no cuida. Permeado por la noción de interdependencia, la articulación entre estas tres perspectivas permite concluir que la valorización de las mujeres y el ámbito de reproducción de la vida, así como las comunidades tradicionales y sus saberes ancestrales son cuestiones / desafíos esenciales para la educación ambiental.
\end{abstract}

Palabras clave: Cuidado; Pandemia; Ecofeminismo; Educación ambiental.

\section{Introdução}

Neste momento, em que enfrentamos o horror de uma pandemia somos obrigadas a reconhecer a importância dos cuidados para nossa sobrevivência e também para a manutenção da vida no planeta. A desvalorização do cuidado, como fonte de princípios, valores e atitudes fundamentais à existência, tem raízes no sistema capitalista-urbano-industrial-patriarcal. Neste sistema, as mulheres, historicamente responsáveis pelo cuidado da vida, sofrem com a 
invisibilização, as injustiças e a exclusão. Apesar disso, estas mesmas atrizes sociais estão na base de movimentos de resistência que enxergam e assumem o cuidado como bandeira de luta politico-comunitária. Nesse sentido, elaboram racionalidades alternativas, que buscam resgatar os saberes ancestrais e os aprendizados da luta popular como base fértil para pensar novos mundos. Aqui, destacamos as resistências das mulheres e dos povos tradicionais como artesãos de práticas de cuidado.

Na primeira parte do texto, tratamos da crise pandêmica, a partir de um olhar voltado às mulheres das classes populares, cujas precárias condições de vida as expõem, mais que a ninguém, aos efeitos do COVID-19. A partir daí, discutimos o significado do cuidar e sua atribuição histórica como de responsabilidade das mulheres, tanto em países ditos desenvolvidos, como em periféricos, como é o caso do Brasil. Refletimos sobre o cuidado como questão de gênero, no contexto de um sistema em que os interesses dominantes se voltam para a produção de lucro e se distanciam da reprodução da vida.

Em seguida, abordamos a questão do rompimento das redes ambientais de cuidados, dentro de um modelo de desenvolvimento que pensa e sente o ambiente como espaço unicamente econômico, desconsiderando sua complexidade socioambiental. Modelo que, ao tomar a natureza como matéria prima morta, provoca profundos desequilíbrios nas relações entre seres humanos e natureza, ameaçando as condições de sobrevivência da espécie sobre a Terra.

Para dialogar com os temas levantados apresentamos algumas concepções do Ecofeminismo, movimento social e teórico que traz a crítica ao sistema mundial capitalistaurbano-industrial-patriarcal como fonte das tendências destrutivas que ameaçam a vida sobre a Terra. Frente ao desafio de preservação da biodiversidade do planeta, nela incluída a vida humana, entendemos a ética do cuidado como uma referência para a educação e condição para a democracia. Por fim, abordamos algumas possibilidades epistemológicas próprias de comunidades e povos tradicionais brasileiros para pensar alternativas de educação ambiental que nos orientem em relação à dois objetivos indissociáveis: a proteção da Terra e a constituição histórica da democracia.

\section{A pandemia e o desvelamento de uma crise de cuidados}

Do final de 2019 para o início de 2020, enfrentamos a primeira grande pandemia do século XXI provocada por um novo vírus - o COVID-19. A nova versão do corona vírus é desconhecida ao nosso sistema imunológico e, por isso, letal para grande parte das pessoas. A 
propagação incrivelmente rápida, o alto número de mortes, o sofrimento dos pacientes e de seus familiares, a rotina cansativa e perigosa dos profissionais da saúde e dos cuidados, o temor coletivo diante da contaminação, o distanciamento social, a quarentena... Novos sentidos e estilos de vida, novas palavras passaram a integrar, nos últimos meses, o cotidiano. As progressões matemáticas são largamente utilizadas para se prever as chances de minimizar a curva de infecção e não sobrecarregar os sistemas de saúde; as pesquisas científicas correm, a todo vapor, na busca por uma nova vacina; a economia se rearranja e busca alternativas de salvação. O ser humano utiliza suas armas mais potentes para resolver o maior desafio dos últimos tempos. A pandemia revela nossa fragilidade e o fato de que estamos todos em um mesmo barco sem rumo.

No entanto, através da exposição de certas contradições, agudizadas nesse momento, percebemos exatamente o contrário: a ação da pandemia não é igualitária, pois não vivemos em sociedades igualitárias. A pobreza e a exclusão tornam alguns grupos, muito mais suscetíveis à doença. No Brasil, por exemplo, as preocupações se voltam para as favelas e comunidades periféricas, onde as famílias, muitas vezes, não têm água nem saneamento para garantir sua proteção. Grande parte destas famílias é chefiada por mulheres negras, que historicamente ocupam os principais postos nos trabalhos domésticos e de cuidados, sempre mal remunerados e fragilmente regulamentados (CARNEIRO, 2011). Com o início da pandemia, muitas destas mulheres foram dispensadas sem garantias nem rendimentos. Com as escolas fechadas, nem mesmo as refeições puderam ser garantidas aos seus filhos. Muitas outras precisaram continuar trabalhando nas casas de família, já que em alguns lugares o trabalho doméstico foi reconhecido como atividade essencial ${ }^{\mathrm{iii}}$. A crise sanitária desvela o que Angela Davis (2020) salientou, em recente palestra sobre o assunto: "De repente, as pessoas se deram conta de que as principais responsáveis pelas atividades essenciais e indispensáveis de cuidados são as mulheres negras.” Essa condição revela a realidade daquelas que sempre foram responsabilizadas pelo cuidado, seja dos patrões ou da própria família, mas que agora são privadas da possibilidade de se cuidar e de cuidar dos seus, pela necessidade urgente de conseguir o sustento da casa, mesmo durante $\mathrm{o}$ isolamento social.

As estratégias adotadas pelos diversos países a respeito dos cuidados com a saúde também estão sendo fortemente expostas nessa crise. Nos EUA a maior mortalidade de pessoas negras evidenciou as condições precárias de saúde a que é submetida esta parcela da população, num país onde o sistema de saúde é totalmente privado. ${ }^{\text {iv }}$ No Brasil, o SUS ${ }^{\mathrm{v}}$, altamente sucateado e precarizado ao longo de décadas, tem sido a única alternativa para milhares de brasileiros. Se as condições da saúde para a classe trabalhadora já eram precárias, a pandemia 
escancarou os efeitos nefastos dos recentes enxugamentos nos gastos públicos para este fim (SANTOS, 2020). Cabe lembrar também, que, como divulgado pela ONU (2020) a maior parte dos profissionais de saúde que estão na linha de frente de combate ao COVID-19 são mulheres: médicas, enfermeiras, fisioterapeutas, nutricionistas e cuidadoras. Muitas destas profissionais vêm denunciando as precárias condições de trabalho e proteção a que são expostas, principalmente nos sistemas públicos. Condições que acentuam a sensação de insegurança neste trabalho, altamente desgastante física e psicologicamente (SAMPAIO, 2020).

A crise provocada pelo COVID-19 trouxe à tona outro fenômeno ainda pouco refletido, gerador de consequências reveladoras - a transferência das atividades do cotidiano para o ambiente privado. Diante da necessidade do distanciamento social, grande parte das empresas, serviços e até mesmo as escolas vêm desenvolvendo suas atividades remotamente. O home office é outra palavra que colonizou nosso cotidiano do dia pra noite. Por traz dessa dinâmica, entretanto, começam a emergir os relatos, cada vez mais frequentes, sobre a sobrecarga e a exaustão provocada por ele. Mais uma vez, quem denuncia tal condição são as mulheres, que viram sua jornada de trabalho triplicar ou quadruplicar, a partir do momento em que precisaram dar conta, não apenas dos cuidados com os filhos (agora em período integral), mas também realizar suas atividades profissionais remotamente. Damos destaque às profissionais da educação, extremamente exigidas no oferecimento de aulas online, produção de materiais didáticos e aprendizado autodidata das ferramentas computacionais, em tempo record. Mesmo que todos estejam em casa, ainda são as mulheres, que, na maioria das vezes, arcam sozinhas com o cuidado e educação dos filhos, condição naturalizada pela maioria dos homens, que se dedica integralmente ao home office.

As raízes patriarcais da nossa sociedade são reveladas através da constatação de que, desde o início da pandemia, a violência doméstica contra mulheres e crianças aumentou significativamente, em várias partes do mundo (ONU, 2020). Estes dados trazem à tona a violência de gênero, que Catalina Oquendo (2020) define como "uma pandemia silenciosa". De forma geral, a permanência em casa e, em consequência, o longo tempo em contato com os agressores dificultam a denúncia. Além disso, a crise econômica, o desemprego e o aumento de ingestão de bebidas alcoólicas significam potencializadores dos conflitos e agressões (TOLEDO, 2020). No campo, essa situação é tão urgente que, no Brasil, algumas organizações criaram uma campanha para dar apoio às mulheres que enfrentam a violência doméstica ${ }^{\mathrm{vi}}$. Folhetos e materiais explicativos vêm sendo distribuídos junto com cestas agroecológicas, doadas às famílias necessitadas. A ideia é ampliar as redes de apoio e socorro de forma segura e articulada. Suas revindicações reforçam que "ficar em casa" é uma questão de saúde, mas 
estar em casa sem violência, dividindo as funções domésticas e de cuidados de forma justa também o são (CARDOSO, 2020). A partir de muitos destes desvelamentos trazidos pela pandemia, nos deparamos com a íntima relação das mulheres com o mundo dos cuidados, questão que exploramos na próxima seção.

\section{O cuidado como questão de gênero}

O tema do cuidado já foi bastante abordado pela história e pela filosofia, no que tange às questões éticas e morais que nos cercam, de forma que este conceito passou por transformações em seu sentido ao longo do tempo (MONTENEGRO 2001). Ainda hoje, quando falamos sobre cuidado é quase instantânea a associação com a dimensão dos sentimentos, da emoção e da alteridade, que remetem ao seu aspecto subjetivo. Por outro lado, há também a questão prática e objetiva de que nenhum de nós, seres humanos, pode chegar à vida adulta sem receber cuidados. Estes, por sua vez, se ampliam, tanto no que se refere aos diferentes níveis de conexão humana desde o âmbito primário da família até a vida em sociedade, abarcando inclusive as relações com o meio ambiente, indispensáveis a nossa existência (BRAUNSTEIN, 2012). Segundo a definição de Cunha et. al. (2019):

Cuidar é pensar-agir descentrando-se de si; é prestar atenção; é solicitude; é desvelo; é preocupação e inquietação pelo bem-estar de outrem; é afeição vital pelos bens comuns; é sentir com e é querer sentir com; é uma forma profunda de partilhar a responsabilidade pela vida em todas as suas formas. O cuidado é, pois, o corazonar que permite que a vida não apenas emerja e se mantenha, mas que possa ser vivida em toda a sua abundância. [...] No nosso entendimento, o cuidado não é apenas uma questão social nem diz respeito somente à domesticidade. Há nele dimensões ontológicas, sociais e epistemológicas que devem ser pensadas e reflectidas (CUNHA et. al., 2019).

Como salienta Boff (1999) a ontologia do cuidado para a constituição do humano está no fato de que cuidar da própria existência, da vida que a cerca e das relações que a sustentam é condição fundamental para conhecer, produzir saberes, adaptar-se. Dessa forma, o "cuidar" reúne em seus sentidos e práticas o diálogo entre razão e emoção já que pode ser entendido como um sentimento, ou uma atividade humana, que, em última instância, busca a superação das adversidades e enfrenta as ameaças à vida. Nesse percurso, produz saberes, tecnologias, rituais, comportamentos e conhecimentos, mediados pela história e pelas relações socioculturais (BRAUNSTEIN, 2012). Apesar de toda a complexidade que envolve esse tema, a dicotomização hierarquizante entre razão e emoção, construída dentro pensamento dominante ocidental, restringiu as atividades de cuidado ao mundo dos sentimentos, do particular, do 
doméstico e do que é considerado "irracional". Nessa perspectiva, o cuidado passou a ser encarado como habilidade nata daquelas que, historicamente, assumiram estes espaços, as mulheres.

Para compreender os motivos que fazem do cuidado uma atividade mais próxima das mulheres, ou seja, influenciada pelo gênero, é importante salientar a construção social que fundamenta tal condição. Nas mais diversas partes do mundo, as mulheres são as principais responsáveis pelo trabalho doméstico de cuidados. A divisão sexual do trabalho é o fenômeno social que estabelece papeis sociais e atividades laborais para homens e mulheres, dentro de cada cultura (KERGOAT, 2009). Nesta divisão, o trabalho masculino sempre ocupou o status da força produtiva necessária ao sistema capitalista, enquanto o trabalho feminino, por muito tempo, foi e é ainda considerado improdutivo, ou mesmo é desconsiderado. ${ }^{\text {vii }}$

Sob essa mesma perspectiva, Vogel (2000) chama a atenção para o caráter indispensável do trabalho doméstico e de cuidados para a reprodução da força de trabalho. Contradizendo a ideia de que este trabalho não estaria inserido no processo de produção capitalista, argumenta que, se não fossem as atividades diárias de alimentação, limpeza, suporte emocional e da própria reprodução, garantida majoritariamente pelas mulheres, a "força de trabalho produtiva" composta pelos homens e pelos futuros trabalhadores (filhos) não teria condições materiais para sobreviver e se renovar. Assim, esse trabalho "invisível”, não remunerado, constitui um pilar importante da manutenção e da exploração do trabalho no sistema capitalista.

Um dos caminhos possíveis para se pensar a desvalorização das atividades de cuidados em nossa sociedade é refletir sobre a desvalorização das mulheres, ou de tudo aquilo que se acredita fazer parte da "natureza feminina", no patriarcado ocidental. Mas vale ressaltar que nem sempre o trabalho feminino foi inferiorizado. Na África, antes da implementação do tráfíco de escravos para as colônias americanas, as sociedades Yorubás possuíam sistemas de divisão do trabalho que não significavam, necessariamente, relações de opressão: as mulheres participavam ativamente das atividades políticas e econômicas e tinham um papel central na organização social da comunidade (OYRWÍMI, apud LUGONES, 2008). Em muitas dessas sociedades, os cuidados com os filhos, por exemplo, eram realizados de forma conjunta ao trabalho no campo (HILL COLLINS, 2019). Entre as civilizações ameríndias, os conquistadores europeus encontraram as mulheres desempenhando atividades diversas no âmbito público e econômico, condição bastante modificada com a colonização (PAREDES e GUZMÁN, 2014).

No entanto, Mies (1993) aponta um marco histórico que representou uma mudança brusca não só no espaço ocupado pelas mulheres, mas também na construção do ideal de mulher 
que seria adotado, a partir daí, nas sociedades ocidentais capitalistas. A empreitada conhecida como "caça às bruxas", que se espalhou por toda a Europa entre os séculos XVI e XVII, além de estabelecer a condenação de milhares de mulheres sob a acusação de bruxaria, representou também, segundo Federici (2019), a repressão às aldeias, atingindo principalmente mulheres camponesas e suas comunidades, que resistiam diante do processo de cercamento dos campos, imposto pela classe dominante feudal pré-capitalista. Em outra esfera, isso significou a perseguição dos conhecimentos e práticas ancestrais das mulheres: o uso das ervas, o cuidado com o corpo e o espírito, a relação holística com a natureza (ibid.). Restringiu também a presença feminina à esfera do lar (seguro), da família (sagrada), do cuidado dos filhos e da servidão ao marido; e distante do contato com a natureza e com a organização política das resistências camponesas (inapropriadas e suspeitas). Para Mies (1993) é a partir desse período que se forjam os valores fundamentais da sociedade ocidental capitalista e patriarcal sobre o papel da "mulher moderna" - passiva, sentimental, incapaz de pensamento racional e limitada ao ambiente doméstico dos cuidados.

Esta concepção hegemônica sobre a mulher e suas funções foi imposta também às colônias recém-descobertas, onde as nativas foram lançadas de suas atividades de subsistência para o trabalho forçado, perseguidas por suas práticas ancestrais; e muitas delas, submetidas à violência e ao casamento nos moldes cristãos, estando restritas ao ambiente privado (PAREDES e GUZMÁN, 2014). De forma semelhante, as mulheres africanas foram trazidas forçadamente de suas terras e de suas atividades comunitárias para trabalharem como escravas. Nesse caso, não experienciaram a restrição ao trabalho doméstico, mas foram inseridas diretamente como mão de obra nos monocultivos coloniais, assumindo as mesmas atividades que os homens. Diante das perversidades da escravidão, foram sistematicamente privadas das atividades de cuidado da família, dos filhos e de sua comunidade, com as quais se ocupavam, anteriormente. $\mathrm{O}$ trabalho de cuidados com os filhos e a casa dos senhores brancos também era realizado por escravas, cujo papel na criação das crianças era fundamental (HILL COLLINS, 2019). Como traz Nascimento (2008), mesmo diante das privações, as mulheres escravizadas, principalmente as mais velhas, reconheciam nos cantos, nas danças, e na contação de histórias - formas de resistência e de transmissão da sabedoria de seus antepassados. Nas senzalas, através dos poucos cuidados que podiam oferecer, buscavam amenizar o sofrimento e manter viva a espiritualidade.

No Brasil, depois do fim da escravidão, que terminou sem nenhuma reparação para os milhares de ex- escravos libertos, grande parte das mulheres negras permaneceram vinculadas aos trabalhos domésticos de cuidados das crianças, dos idosos e da casa (GONZALES, 2008). 
Essa realidade se estende até os dias de hoje: as mulheres negras ocupam a maioria dos postos de trabalho de atividades manuais, do trabalho doméstico terceirizado e dos trabalhos de cuidados em geral. São estas também algumas das profissões mais mal remuneradas, desregulamentadas e sujeitas à insalubridade, abarcando, inclusive, altos índices de trabalho infantil e de "escravidão moderna" (GONZALES, 2008). A desvalorização de tais funções aliada à exclusão e discriminação que sofrem as mulheres negras, fazem das famílias sustentadas por estes trabalhos (de cuidado) as mais pobres do país. Sueli Carneiro (2011) demonstra que as famílias chefiadas por mulheres negras ainda são aquelas com menor poder aquisitivo, classificadas dentro do chamado "matriarcado da miséria". Neste sentido, as reflexões de Federici (2019) elucidam as disparidades que permanecem presentes até hoje:

Há uma diferença importante entre o regime que o capitalismo impôs à classe trabalhadora na Europa e o colocado nos lugares onde existiu escravidão. Na Europa, foi constituída essa classe de esposa- trabalhadora em tempo integral. Mesmo que muitas mulheres também trabalhassem fora de casa, era entendido que o trabalho primordial era o de cuidar dos trabalhadores. Isso foi parte de um projeto capitalista de investir na classe trabalhadora dando a ela uma casa e um salário para que fosse mais produtiva. Na África e na América Latina, essa realidade sempre foi bem diferente. Porque o Estado nunca esteve preocupado em investir nos trabalhadores, mas sim em consumi-los. Então a tarefa das mulheres nunca foi reproduzir sua comunidade, mas reproduzir a vida dos ricos (FEDERICI, 2019, p. 14).

Assim, no que diz respeito às mulheres, podemos entender que a dimensão dos cuidados assume contornos distintos, quando consideramos a realidade dos países com um histórico colonial escravocrata. Realidade que evidencia a necessidade de avaliar as dinâmicas de opressão e de construção do lugar do cuidado de forma interseccional, ou seja, considerando raça, gênero e classe, como dimensões inseparáveis (GONZALES, 2008).

A restrição do trabalho de cuidados ao âmbito privado e ao particular o torna desarticulado das responsabilidades sociais do Estado em relação à oferta de serviços essenciais (MERCHANT, 1992) ${ }^{\text {viii }}$. A atual política neoliberal mundial, preconizada por órgãos internacionais, como o FMI e o Banco Mundial, impõe a progressiva diminuição da participação do Estado na economia e na definição de gastos públicos. Assim, impacta os programas sociais e, nos países mais pobres, deixa as classes populares cada vez mais vulneráveis (FOLADORE, 2002). A garantia de serviços públicos é fundamental para a melhoria das condições de vida da população e, portanto, para o fortalecimento da democracia. A precarização afeta principalmente as mulheres e crianças das classes populares, fato que se relaciona com a crise dos cuidados. 


\section{O rompimento das redes ambientais de cuidados}

Quando ampliamos a perspectiva do cuidado, de forma que ele não se restrinja apenas às relações entre humanos, podemos acessar outras esferas de sua manifestação. Considerando os cuidados como componentes ontológicos do humano, tudo leva a crer que também sejam essenciais para nossa relação com o mundo, com a natureza e em sociedade. A atual crise ambiental diz bastante sobre a forma como as sociedades modernas desenvolveram suas relações com o ambiente (SHIVA, 2003). Isso quer dizer que, a partir de certo momento da história, impôs-se um modelo de civilização que se relaciona com a natureza de forma tal que incompatibiliza a produção material com a sobrevivência de outras espécies e com a manutenção da integridade do planeta. Significa dizer que este modelo vem produzindo mudanças tão profundas nos ciclos naturais da Terra, que comprometem não apenas outros seres, mas também a própria sobrevivência humana (ibid.).

Hoje, sabemos que a biodiversidade é uma das chaves para a estabilidade e resiliência ecológica. É a partir da biodiversidade que os ecossistemas, mesmo sob impactos, conseguem se reestabilizar e manter seus ciclos de produção de vida e também as condições ambientais necessárias para aqueles que os habitam. Já se sabe que as interações entre as formas de vida diversas formam teias complexas e fluxos de energia, que vão definir aspectos globais, essenciais à nossa sobrevivência, como é o caso do clima. Nessa perspectiva, contribuir com a biodiversidade e preservá-la devem ser consideradas formas de cuidado com o planeta, com a natureza, com todos os seres vivos (SHIVA, 2003).

Há algum tempo, a preservação da biodiversidade vem sendo atrelada à criação das áreas protegidas, partindo-se do pressuposto de que, diante dos intensos impactos humanos sobre as demais espécies, a único caminho para a sua preservação é o isolamento. No entanto, como afirma Diegues (2001) não é bem assim que a biodiversidade foi mantida ao longo do tempo. $\mathrm{O}$ autor salienta que as áreas do planeta em que hoje encontramos as maiores taxas de biodiversidade também são aquelas que, por mais tempo, foram ocupadas por certas populações, que, ao longo das gerações, e diante das interações com os ecossistemas, desenvolveram formas de subsistência adaptadas. No caso do Brasil, as populações indígenas, quilombolas, camponesas, ribeirinhas, caiçaras e muitas outras, conhecidas como populações tradicionais, vêm desempenhando estas formas de subsistências, ao longo dos séculos ix (DIEGUES, 2001). Seguindo o mesmo raciocínio, Vandana Shiva (2003) reitera que as interações entre estas populações e a biodiversidade produzem culturas também diversas: 
A diversidade é característica da natureza e a base da estabilidade ecológica. Ecossistemas diversificados fazem surgir formas de vida e culturas diversificadas. A co-evolução de culturas, formas de vida e habitats têm conservado a diversidade biológica nesse planeta. A diversidade cultural e a diversidade biológica andam de mãos dadas (SHIVA, 2003, p. 85).

A diversidade biológica é tida como um valor importante quando consideramos, por exemplo, a economia de subsistência e os serviços de cuidados da comunidade A diversidade de plantas oferece a possibilidade de utilização em medicamentos caseiros; a qualidade da nutrição das crianças e adultos vai depender da diversidade de alimentos e possibilidade da seleção daqueles mais nutritivos; a interconexão e manutenção das florestas assegura sombra, ar fresco, disponibilidade de água, combustível, caça e forragem para as plantações. Estas interações geram também os chamados conhecimentos tradicionais, que mesclam os saberes empíricos (manejo da terra, leitura dos ciclos da natureza, conhecimento da biodiversidade) às perspectivas espirituais e cosmológicas (SHIVA, 2003). Como explica esta autora "os conhecimentos ecológicos profundos e sofisticados da biodiversidade originam regras culturais para a preservação, que se refletem em noções de sacralidade e tabus" (ibid., p. 86).

A concepção da terra e das forças da natureza como sagradas faz parte das cosmologias de uma grande diversidade de povos no mundo inteiro. O movimento Chipko, na Índia dos anos 70, reuniu comunidades camponesas e tribais em defesa das florestas sagradas, contra a exploração madeireira (SHIVA, 1995). Na América Latina, a defesa de Pacha Mama, dos rios, florestas e territórios contra os projetos mineradores está presente nas lutas de resistência da maioria dos povos originários (HOMAND, 2016) ${ }^{\mathrm{x}}$. No Brasil, desde a época colonial, a interação entre indígenas e africanos (principalmente de origem banto) tiveram como ponto de interseção a noção de sacralidade da terra, dos elementos da natureza e dos ancestrais, presentes na cosmologia de ambos os povos. Esses valores estão ainda entranhados na cultura e nas práticas religiosas de alguns povos tradicionais (LOPES, 2008).

Apesar disso, estas concepções estão distantes, muitas vezes, totalmente opostas ao pensamento dominante. Desde o advento das revoluções industriais capitalistas na Europa, as relações com a natureza e o impacto da ação humana em seus ciclos mudaram bruscamente:

La revolución industrial convirtió la economía de prudente administración de los recursos para el sustento y satisfacción de las necesidades básicas en un proceso de producción de bienes para hacer el máximo de ganancias. El industrialismo creó un ilimitado apetito de explotación de recursos, y la ciencia moderna proporcionó la licencia ética y cognoscitiva para que dicha explotación fuera posible, aceptable y deseable (SHIVA, 1995, p. 23). 
A instituição de um sistema que exige uma quantidade cada vez maior de matéria prima para a produção de uma variedade cada vez maior de objetos de consumo, articulado com a crescente exploração do trabalho humano em prol da acumulação de capital, acabou por desintegrar os modos de vida mais próximos à natureza (FEDERICI, 2019).

Hoje, existe ainda uma grande quantidade de grupos cujos modos de vida mantêm uma relação mais harmônica com a natureza, entretanto, estes se encontram fortemente ameaçados. Os processos de globalização ${ }^{\mathrm{xi}}$ impõem, para o resto do mundo, os padrões de desenvolvimento dos países industrializados (SANTOS, 2002). Não é por acaso que o estabelecimento de projetos desenvolvimentistas afeta primordialmente as populações tradicionais. A maior parte dos conflitos ambientais em todo mundo se dá exatamente pelo embate de diferentes visões sobre as relações humanas com a natureza: para os empresários, governos e classes dominantes ela é fonte de lucro e crescimento econômico, para as populações locais é fonte de subsistência, sobrevivência e de manutenção de seu modo de vida. Como argumenta Shiva:

[...] as comunidades estáveis, em harmonia com seu ecossistema, sempre protegem a biodiversidade. Somente quando as populações são desalojadas por represas, minas, fábricas e agricultura comercial é que sua relação com a biodiversidade passa a ser antagônica, em vez de cooperativa. O desalojamento de pessoas e a destruição da diversidade andam de mãos dadas, e pessoas desalojadas destroem mais ainda a biodiversidade como um efeito secundário das causas principais de destruição identificadas anteriormente (SHIVA, 2003, p. 94).

É importante ressaltar que estes processos também geram resistências. Muitos movimentos sociais vêm assumindo a defesa dos territórios e dos bens naturais coletivos como bandeira de luta por justiça e democracia. No Brasil, é o caso do Movimentos dos Atingidos por Barragens (MAB), do Movimento dos Trabalhadores Sem Terra (MST), dos Atingidos pela Indústria do Petróleo e muitos outros. Estes movimentos populares abarcam grupos de várias origens em grande parte camponeses, que também representam importantes mantenedores da biodiversidade e da subsistência. Muitos deles atuam como protetores de rios, bacias e florestas. Destacam-se nestes movimentos a presença e ação estratégica das mulheres, historicamente envolvidas na gestão, preservação e luta pelos bens naturais coletivos que são necessários à sobrevivência das comunidades e à manutenção da biodiversidade (SHIVA, 1995). Apesar de sua atuação importante elas são, assim como seus movimentos, alvo de invisibilização e/ou criminalização pelas mídias, empresas e também por parte dos governos neoliberais (MERLINSK, 2017).

$\mathrm{Na}$ América Latina, as mulheres negras e indígenas das classes populares são as mais afetadas pelas catástrofes ambientais e pelos impactos trazidos pelo neoextrativismo, pois são 
as principais mantenedoras da vida cotidiana das comunidades (ÁVILA, 2019). Diante de situações de escassez e desestruturação dos territórios, produzidas por estas atividades, recai sobre elas a tarefa de produzir os meios de sobrevivência (ibid.). Ao mesmo tempo, ao longo das gerações, as mulheres foram as principais responsáveis pelos trabalhos de cuidados no cultivo e preparação dos alimentos, na seleção e conservação de sementes, na utilização das plantas na cura dos enfermos: uma série de atividades realizadas com os recursos disponíveis na natureza, que, de forma equilibrada, geraram técnicas e conhecimentos transmitidos de forma intergeracional (SHIVA, 1995).

Sob esta perspectiva, a desterritorialização e o desenraizamento de seus modos de vida, aliados à destruição dos habitats, convergem como as principais causas da perda da biodiversidade (ibid.). Estudos apontam, há algum tempo, que o surgimento de novas doenças infecciosas, como é o caso da provocada pelo novo coronavirus, tem forte relação com a expansão urbana em direção aos habitats selvagens (cada vez mais fragmentados) e com mudanças nos hábitos e interações entre espécies selvagens e seres humanos (WOOD et. al., 2020). Nesse sentido, a destruição e fragmentação das florestas em prol dos plantios monoculturais de exportação, por exemplo, vêm provocando diversas modificações no equilíbrio dos ecossistemas (SHIVA, 2020). Somado a isso, em todo o mundo, especialmente na América Latina, tornam-se cada vez mais frequentes os desplazamientos e conflitos ambientais provocados por políticas neoliberais (MERLINSK, 2017). Há muitos indícios de que as comunidades tradicionais e os defensores de seus territórios estão sendo mais fortemente afetados pelos efeitos da pandemia. ${ }^{\text {xii }}$

Frente a essa realidade, voltamos o olhar para as formas pelas quais vem se dando o rompimento das redes de cuidados construídas pelos seres humanos, ao longo de sua existência. A eliminação constante de grupos e modos de vida que ainda preservam estas redes, assim como o mergulho cada vez mais profundo num sistema incontestavelmente insustentável, trazem à tona uma tragédia anunciada. É diante deste contexto desfavorável que somos desafiadas a procurar alternativas.

\section{Ecofeminismo: entre a perplexidade e a esperança}

A presença massiva das mulheres das classes populares em defesa de seus territórios nos conduz a um conjunto de análises e proposições a respeito da situação atual e do futuro da vida na Terra. Ao afirmar, nas ultimas décadas do século passado, uma relação entre opressão 
patriarcal e desequilíbrio ambiental, o Ecofeminismo articula dois importantes movimentos: o Ecologismo e o Feminismo ${ }^{\text {xiii }}$.

De acordo com as análises de Mies e Shiva $(1997,1998)$ a ânsia mercadológica que produziu o quadro socioambiental em que estamos situados pode ser classificado como enfermidade mundial. Essa enfermidade tem como pano de fundo uma visão da natureza como algo a ser dominado e se deve a uma cosmologia e a uma antropologia que dicotomizam estruturalmente a realidade, definindo uma oposição hierárquica entre as partes. Assim, a natureza aparece subordinada aos seres humanos, a mulher ao homem, a criança ao adulto, o consumo à produção, o local ao global, numa lógica em que uma parte acaba sempre sobrevivendo mediante a subordinação e apropriação da outra. No pensamento ecofeminista, portanto, assim como as relações capitalistas de produção revelam o domínio da natureza pelo ser humano, as relações patriarcais de reprodução revelam o domínio das mulheres pelos homens (CORRAL; OLIVEIRA, 1992; MERCHANT,1992).

As descobertas e proposições no campo da biotecnologia, engenharia genética e tecnologia reprodutiva, por exemplo, reafirmaram a constatação de que o paradigma da ciência tem um caráter tipicamente patriarcal. Por esta razão, o olhar ecofeminista não está voltado apenas para as implicações da ciência e da tecnologia sobre as mulheres, mas também sobre as plantas, os animais e a agricultura. A luta pela libertação das mulheres neste movimento não é isolada, mas parte de uma luta mais ampla pela conservação da vida no planeta. Para isto, no entanto, é necessário desconstruir o paradigma reducionista, surgido entre os séculos XV e XVIII, no bojo da Revolução Científica, que se apresenta como um sistema de conhecimentos universais desprovido de valores que, graças à lógica de seu método, presume ter alcançado uma compreensão sobre a vida, o universo, enfim, sobre quase todas as coisas.

Para o ecofeminismo, o dilema socioambiental que hoje enfrentamos está relacionado a uma concepção de mundo e a uma ciência que concebe a realidade como uma máquina e não como um organismo vivo. Para ultrapassar os limites da natureza, a ciência reducionista fragmentou o organismo, no pensamento e na prática, da mesma forma que separou razão e emoção, permitindo que o conhecimento das partes de um sistema se apresente como conhecimento da totalidade. O princípio da divisibilidade possibilitou a abstração de conhecimentos, independentemente de seu contexto, criando critérios de validade baseados na alienação e na não participação, que se apresentam como objetividade. A concepção reducionista de mundo, a revolução industrial e a economia capitalista são os componentes filosófico, tecnológico e econômico de um mesmo processo. O reducionismo dá sustentação científica a esta lógica (MIES e SHIVA, 1998). 
No paradigma reducionista, um bosque é reduzido à madeira comercializável, e esta à fibra de celulose destinada à indústria papeleira. O passo seguinte é o da manipulação dos solos, dos bosques e dos recursos genéticos para incrementar a produção de pasta de madeira. Esta distorção se legitima cientificamente apresentando-a como um incremento global da produtividade, desconsiderando a possível redução da quantidade de água gerada pelo bosque ou a destruição da diversidade de formas de vidas que constituem uma comunidade florestal (MIES e SHIVA, 1997, p.43). Esta lógica permite colonizar e controlar o que a vida ofereceu a todos os seres como dádiva gratuita e capaz de autorreprodução, sob o pretexto de que os ritmos naturais são demasiadamente lentos e primitivos e de que é necessário superá-los para gerar abundância e liberdade. Para Mies e Shiva (1997) as mulheres, a natureza e os povos do terceiro mundo são as colônias da civilização industrial-patriarcal: "Sem a sua colonização nos moldes da apropriação predatória (exploração), não existiria a famosa civilização ocidental nem seu paradigma de progresso e, sobretudo tampouco sua ciência natural e sua tecnologia" (idem, p. 69). Assim, a ameaça à continuidade da vida sobre o planeta é resultado "de um casamento fatal entre cérebro e violência, que o modelo patriarcal, de maneira muito eufemística, chama poder" (ibid.).

Fazendo uma crítica ao cartesianismo e ao empirismo, o Ecofeminismo diz que, para ser capaz de violentar a natureza, o homo cientificus teve que se separar, ou melhor, que se situar como superior à natureza, esquecendo sua condição animal, valorizando aquilo que o distingue enquanto espécie e desprezando o que o caracteriza enquanto ser que é parte integrante e dependente desta mesma natureza planetária. A separação entre sujeito e objeto é a base da concepção formada sobre o conhecimento: a ideia de que pertence aos humanos tudo que não é humano - as terras, as águas, os vegetais, os animais, os minerais. Este afastamento conduz à derrubada das barreiras morais que permitem à ciência realizar pesquisas no campo da tecnologia genética, reprodutiva e nuclear, ou que legitimam a ocupação e exploração de territórios comunitários em prol do lucro privatista. Da mesma forma, suprime ou subvaloriza outros caminhos de conhecimento, como a intuição, os sentidos, os sentimentos, a experiência.

Na contramão dessa perspectiva, o Ecofeminismo nos ensina que a transição para um meio ambiente global sustentável e uma economia humana que satisfaça as necessidades das pessoas se fundamentaria em duas relações dialéticas: uma entre produção e ecologia e, outra, entre produção e reprodução. É a partir desta perspectiva que uma ética do cuidado, ou sensível ao cuidado, aparece como proposição teórica e prática para o enfrentamento da lógica que perpetua este sistema de opressões (ROSENDO, 2015). Sob o olhar ecofeminista o cuidado é entendido como elemento fundamental para a tomada de decisões, dentro de um pensamento 
ético e moral, que considere valores como respeito, responsabilidade, afetividade e interdependência entre as espécies.

$\mathrm{Na}$ prática ambiental, significa dizer que a valorização dos cuidados, ou de uma perspectiva ética a partir do cuidado, carrega um potencial de criação e manutenção de interações coletivas mais respeitosas e justas (ESTÉVES, 2019). Esta proposição carrega também a crítica ao modelo legalista e universalista com a qual as questões ambientais vêm sendo tratadas há muito tempo, nas sociedades ocidentais. As leis e a justiça, muitas vezes, são pautadas pela perspectiva dos grupos dominantes, baseada na objetividade, imparcialidade, sob a perspectiva única dos direitos (faço porque tenho direito, não faço para não infrigir o direito do outro). Condição que, nem sempre é cumprida quando se trata dos direitos dos povos tradicionais e das mulheres que se opõem aos interesses do capital e que desconsidera que as relações socioambientais dos diversos grupos humanos são complexas, diversas e abarcam outras dimensões que não apenas a utilitarista: a sacralidade dos territórios, o direito a subsistência saudável, a afetividade e responsabilidade com as outras formas de vida, o valor intrínseco de existência de espécies e elementos não humanos.

A centralidade do cuidado na criação de outro paradigma civilizatório, comum às revindicações dos movimentos de mulheres, dos povos tradicionais e das perspectivas ecofeministas pode representar um valioso caminho no enfrentamento da desvalorização da vida e na busca alternativas pedagógicas que se alinhem a esta perspectiva.

\section{Educação ambiental e cuidados}

Pensar a educação ambiental sob a perspectiva do cuidado significa reconhecer as práticas e os trabalhos de cuidados como componentes fundamentais para as transformações nas relações socioambientais, na direção de um novo paradigma. A crítica ecofeminista nos revela uma verdadeira guerra à natureza pelo modelo civilizatório capitalista ocidental, cujas práticas e valores reforçam processos destrutivos das teias da vida, da subsistência e da autonomia dos povos. O enfrentamento dessa realidade requer transformações profundas, capazes de substituir o ethos de destruição vigente por outro, de respeito e interdependência (SHIVA apud SVANPA, 2015).

Identificar e reconhecer as lutas socioambientais populares como experiências de enfrentamento à racionalidade capitalista, individualista, antropocêntrica e androcêntrica são os primeiros passos para a formulação de uma educação ambiental que busque alternativas a este modelo. As resistências e (re) existências das mulheres se destacam por reafirmar a 
importância de nossas bases primeiras de reprodução da vida (SVAMPA, 2015). O alimento, a água, a terra, a paz, o afeto, a vida comunitária são todos elementos indispensáveis à nossa existência. A perspectiva de uma cultura de cuidados, por sua vez, pode possibilitar o desenvolvimento de relações mais harmônicas e justas, que se contraponham à perspectiva de dominação e privatização da natureza (ibid.).

Apesar do campo da educação ambiental, em sua vertente hegemônica, priorizar a visão tecnicista, individualista e pragmática ${ }^{\mathrm{xiv}}$, existe o empenho na busca de alternativas orientadas por outras vertentes (LAYRARGUES e LIMA, 2014). As concepções dos grupos marginalizados, dos povos tradicionais e dos movimentos populares trazem uma história ambiental de violências, injustiças, remoções, desplazamientos e muitos outros processos que estão na base do desmantelamento de relações ancestrais com a vida. Por seu caráter crítico, as perspectivas constituídas em movimentos de resistência, engendram aprendizados, saberes e valores produzidos coletivamente (STORTI et. al., 2016). O resgate e fortalecimento de conhecimentos ancestrais que abrigam outros modos de sentir, pensar e estar no mundo são desafiadores do modelo vigente. Por trazerem consigo outras racionalidades e epistemologias, são combustíveis potentes para a criação e experimentação de práticas político-pedagógicas engajadas e libertadoras.

Os movimentos de auto-organização das mulheres do campo e das florestas vêm levantando questionamentos importantes sobre alguns conceitos caros à educação ambiental crítica e comunitária, tais como a busca por outras racionalidades, a existência de outras sustentabilidades, a defesa dos bens naturais comuns e a valorização de saberes ambientais populares (OLIVEIRA et. al. 2020). Ao discutirem o tema da sustentabilidade, posicionam-se contrariamente à noção hegemônica, vinculada ao modelo de desenvolvimento capitalista. Questionam a possibilidade de existência de qualquer tipo de sustentabilidade diante do neoextrativismo e do neoliberalismo que assolam a América Latina (PAREDES e GUZMÁN, 2014). Na perspectiva dessas mulheres, a sustentabilidade depende da garantia de permanência em seus territórios e de autonomia frente aos processos de reprodução de sua vida individual e comunitária.

A soberania alimentar é uma das bandeiras que materializam essa perspectiva: ser sustentável é poder ser livre para produzir comida de qualidade a partir de seu território, travando relações sociais de trabalho de reciprocidade, não de exploração. A sustentabilidade, portanto, é concebida a partir da noção dos direitos básicos, da subsistência e de qualidade de vida para mulheres, homens, crianças e idosos. Não como um "selo verde", apresentado por 
empresas e projetos ditos sustentáveis, que seguem protocolos engendrados na economia de mercado e desrespeitam os direitos das comunidades e da natureza.

No Brasil, Cunha e Valle (2018) destacam a agroecologia como fonte de racionalidades alternativas que inspiram pedagogias ecofeministas transformadoras. O movimento de agroecologia sempre contou com a participação das mulheres camponesas em sua elaboração. Nele, o cuidado e a interdependência são considerados como pontos centrais nas relações - tanto produtivas, quanto comunitárias e ambientais - redimensionam o "ser" e o "estar" no planeta. Abrem as portas para relações sociais outras, que produzem conhecimentos e formas de aprendizado também distintas, entrelaçando os saberes populares e ancestrais às inovações tecnológicas; e, principalmente, reinventando as relações de trabalho e de consumo.

Movimentos sociais como o MST, Movimento de Mulheres Camponesas (MMC), a Via Campesina vêm construindo a agroecologia como forma de resistência contra o modelo hegemônico de produção de alimentos ${ }^{\mathrm{xv}}$. Nesse caminho nos ensinam que a garantia de uma alimentação saudável (livre de veneno) essencial à nossa sobrevivência está diretamente relacionada às condições de vida e trabalho dos agricultores e à manutenção dos cuidados com a terra e os ecossistemas (SILIPRANDI, 2012). Dialogam, portanto, com a perspectiva ecofeminista, que exige uma nova conexão entre ciência e responsabilidade, fundamentada no fato de que a Terra e seus recursos são limitados, como nossa vida e o tempo também o são. Uma sociedade sustentável pressupõe que os humanos se tratem como iguais nas relações pessoais, familiares e políticas, e como parceiros iguais da natureza não humana, oferecendolhe espaço, tempo e cuidados.

A valorização, o resgate e legitimação da produção de conhecimento destas comunidades também são aspectos desenvolvidos por tais movimentos. Os saberes populares e ancestrais, passados às gerações mais jovens através da oralidade, engendram pedagogias que se desenvolvem na práxis, na experiência do cotidiano, mas também a partir de relações ancestrais de cuidado e respeito com a natureza. Estes saberes estão contextualizados à realidade das comunidades e abarcam diversos aspectos, como, por exemplo, os conhecimentos das plantas medicinais e sua utilização, as tecnologias ancestrais de seleção genética e as técnicas de preservação e troca de sementes, os conhecimentos sobre o clima e sua interelação com a produção e muitos outros. Assim, a educação ambiental tem muito a aprender com as trocas de saberes que acontecem nas rodas de conversa das mulheres. Nas feiras, nos encontros indígenas, nas farmácias populares quilombolas, em inúmeros e diversos espaços de resistência e de esperança, outros modos de relação com a vida são gestados. 


\section{Considerações}

A partir das reflexões levantadas reforçamos a indispensabilidade da dimensão dos cuidados em nossa vida, tão fortemente acentuada nesta crise pandêmica. Enfatizamos a necessidade de valorização do trabalho de cuidados e daquelas que o exercem no cotidiano, direcionando-nos especialmente às mulheres das classes populares. Da mesma forma, reiteramos a ideia de que os povos tradicionais, os movimentos socioambientais de mulheres e o ecofeminismo vêm traçando novos horizontes e construindo alternativas sociais, políticas e epistêmicas que resistem à lógica capitalista antropocêntrica patriarcal. Não é o caso de delegar a salvação do planeta a esses grupos, já tão marginalizados pelo sistema hegemônico. Mas de aprender com as mulheres, em suas lutas, resistências e (re) existências, os saberes de cuidado,

Por outro lado, como atuar na perspectiva de que as crianças e jovens, em espaços de educação formal, aprendam a valorizar os conhecimentos que nascem das vivências, das lutas de mestres e mestras, seus ancestrais? Para nós, a resposta é: trazendo-os em carne e osso, abrindo, na escola, espaços às suas vozes, aos seus saberes; assumindo concepções e praticas educativo-pedagógicas que os respeitem como legítimos herdeiros e herdeiras culturais de comunidades e povos tradicionais e originários brasileiros, aliás, como todos e todas nós o somos. O esquecimento desta condição de hereditariedade é um dos efeitos principais do processo de epistemicídio que moldou o nosso olhar para a História e viabilizou a conquista do continente americano para a consolidação do capitalismo. Em uma perspectiva de respeito à democracia, o resgate de modos de viver pautados em éticas de cuidado que estão presentes em nossa ancestralidade é condição para a superação da crise ambiental capitalista, geradora da atual pandemia,

\section{Referências}

ÁVILA, M. B. Mujer y naturaleza. De los sentidos de la dominación em el capitalismo y em el sistema patriarcal. In: CELIBERTI, L. (coord.) Las bases materiales que sostienem la vida. Perspectivas ecofeminstas. Montevideo: Cotidiano Mujer - Colectivo Ecofeminista Dafnias:, 2019.

BRAUNSTEIN, H. R. Ética do cuidado. Das instituições do cuidado e pseudo cuidado. Tese de doutorado, USP, São Paulo, 2012.

BOFF, L. Saber cuidar: Ética do Humano - Compaixão pela Terra. Petrópolis, Vozes, 1999. 
CARDOSO, B. Ficar em casa é questão de saúde. In: ANA-GT Mulheres; ASA; ABA; CONTAG. Dividir tarefas e viver sem violência também. Live. Campanha- pela divisão justa do trabalho doméstico. 04/06/2020.

CARNEIRO. S. Racismo, sexismo e desigualdade no Brasil. São Paulo: Selo Negro, 2011.

CORRAL, T.; OLIVEIRA. R.D. (org.). Terra Femina. Rio de Janeiro, Idac/Redeh, 1992.

CUNHA, T.; VALLE, L. P. O respeito à economia da vida e as pedagogias ecofeministas. Reflexões sobre a prática da agroecologia e do hamutuk. Otra Economía, v. 12, n. 22, p. 238$252,2019$.

CUNHA, T.; VALLE, L. de P.; VILLAR-TORIBIO, C. "Cuidado", Dicionário Alice. 2019. Disponível em:

https://alice.ces.uc.pt/dictionary/?id=23838\&pag=23918\&id_lingua=1\&entry=25288. ISBN: 978-989-8847-08-9. Acesso em: 23 maio /2020.

DAVIS, A. Feminicídio, genocídio e pandemia. Live: Conversas Impertinentes. Universidade Estadual do Amazonas (UEA) e TV Lepete, 04/06/2020. Disponível em: www.youtube.com/tvlepete. Acesso em 04 jun. 2020.

DIEGUES, A. C. S. O mito moderno da natureza intocada. São Paulo: HUCITEC, 2001.

ESTÉVEZ, A. D. Ecofeminismo: Poniendo el cuidado en el centro. Ene revista de enfermeria, Madrid, v. 13, n. 4, 2019.

FEDERITI, S. Mulheres e caça às bruxas: da idade Média aos dias atuais. São Paulo: Boitempo, 2019.

FOLADORE, G. Avanços e limites da Sustentabilidade Social. Revista paranaense de Desenvolvimento, Curitiba, n. 102, p. 103-113, 2002.

GONZALES, L. Mulher negra. In. Nascimento, E. L. (org.) Guerreiras da Natureza. Mulher negra, religiosidade e ambiente. São Paulo: Selo Negro, 2008.

HILL COLLINS, P. Pensamento feminista negro. São Paulo: Boitempo, 2019.

HOMAND, J. Berta Cáceres y el mortal costo de defender la tierra y la vida. 2016. Disponível em: https://www.ecologiapolitica.info/?p=6085. Acesso em: 13 maio 2020.

KERGOAT, D. Divisão Sexual do trabalho e relações sociais de sexo. In: HIRATA, Helena et. al. (Org.). Dicionário crítico do feminismo. São Paulo: UNESP, 2009, p. 67-75.

LAYRARGUES, P. P., LIMA, G. F. C. As macrotendências político-pedagógicas da educação ambiental brasileira. Ambiente \& Sociedade. São Paulo v.17, n.1, p. 23-40, 2014.

LOPES, N. Bantos, índios, ancestralidade e meio ambiente. In. Nascimento, E. L. (org.) Guerreiras da Natureza. Mulher negra, religiosidade e ambiente. São Paulo: Selo Negro, 2008 . 
LUGONES, M. Colonialidad y gênero. Tabula Rasa. Bogotá. n. 9, p.73-101, 2008.

MERCHANT, C. Radical Ecology: The Search for a Livable World. New York: Routledge, 1992.

MERCHANT, C. "Ecofeminismo”. In: CORRAL, T.; OLIVEIRA, R. D. (orgs.).Terra Femina. RJ, Idac/Redeh, 1992 b.

MERLINSK, G. Los movimientos de justiça ambiental y la defesa de ló común em América Latina. Cinco tesis em elaboración. In: ALIMONDA, H.; PÉREZ, C. T.; MARTÍN, F.(Coord.). Ecología Política Latino Americana. Pensamiento crítico, diferencia latinoamericana y rearticulación epistêmica. Ciudad Autónoma de Buenos Aires: CLACSO. 2017.

MIES, M. O dilema do homem branco: a procura do que deve ser destruido. In: MIES, M.; SHIVA, V. Ecofeminismo. Lisboa: Instituto Piaget, 1993.

MIES, M.; SHIVA, V. Ecofeminismo: teoria, crítica y perspectivas. Barcelona, Icaria editorial, 1997.

La praxis del ecofeminismo. Biotecnologia, consumo y reproducción. Barcelona, Icaria Editorial, 1998.

MONTENEGRO, T. O cuidado e a formação moral na educação infantil. São Paulo, EDUC, 2001.

NASCIMENTO, G. M. Grandes mães, reais senhoras. In. Nascimento, E. L. (org.) Guerreiras da Natureza. Mulher negra, religiosidade e ambiente. São Paulo: Selo Negro, 2008.

OLIVEIRA, C. A. G.; ROJAS, L. A. P.; PRADA, K. A. F.; SALGADO, S. D. C. O que os Movimentos de Mulheres e os Ecofeminismos do Sul nos ensinam? Apontamentos para a Educação Ambiental de Base Comunitária. In: ACCIOLY, I. ; PELACANI, B.; SÁNCHEZ, C. (Org.) Dossiê: Educação Ambiental: Insurgências, Re- existências e esperanças. Ensino, saúde e ambiente. Número Especial, p.180-204, 2020.

ONU - Vozes das mulheres nas linhas de frente da Covid-19, 17/04/2020. Disponível em: $\mathrm{http}: / / \mathrm{www}$.onumulheres.org.br/noticias/vozes-das-mulheres-na-linhas-de-frente-da-covid19/. Acesso em: 11 jun. 2020.

OQUENDO, C. "A violência de gênero é uma pandemia silenciosa". Disponível em: https://brasil.elpais.com/sociedade/2020-04-09/a-violencia-de-genero-e-uma-pandemiasilenciosa.html. 08/04/20 Acesso em: 19 maio 2020.

PAREDES, J. C.; GUZMÁN, A. A. El tecido de la rebeldia. ¿Que ES el Feminismo Comunitário? Bases para la despatriarcalización. Moreno Artes Gráficas: Bolívia, 2014.

ROSENDO, D. Sensível ao cuidado: uma perspectiva ética ecofeminista. Revista Territórios \& Fronteiras, Cuiabá, v. 8, n. 2, p. 412- 418, 2015. 
SAMPAIO, C. Em silêncio e segurando cruzes, enfermeiros protestam na porta do Planalto. Brasil de Fato. Disponível em: https://www.brasildefato.com.br/2020/05/01/em-silencio-esegurando-cruzes-enfermeiros-protestam-na-porta-do-planalto

SHIVA, V. Sobre el Coronavirus: de los bosques a nuestras granjas, a nuestro microbioma intestinal, 2020. Disponível em: https://navdanyainternational.org/es/vandana-shiva-sobre-elcoronavirus/. Acesso em: 30 abr. 2020.

A monocultura da mente. Perspectivas da biodiversidade e da biotecnologia. São Paulo: Gaia, 2003.

Abrazar la vida. Mujer, ecologia e supervivência. Madri: Horas y Horas. 1995.

SILIPRANDI, E. Mulheres agricultoras no Brasil: sujeitos na luta por soberania e segurança alimentar. Pensamento iberoamericano. p. 169-183, 2012.

SANTOS B. S. A cruel padagogia do vírus. Almedina: Coimbra, 2020.

Os processos de globalização. In: SANTOS, Boaventura de Souza (Org.). Globalização: fatalidade ou utopia? Porto: Afrontamento, 2002.

STORTTI, M.; MENEZES, A. K.; SANCHÉZ, C. In: PUNGGIAN,Cleonice; BOUHID, Roseantony; FONTOURA, Helena A. (org.) Anais Seminário de Justiça Ambiental, Igualdade Racial e Educação n.5, p. 17-31, 2016.

SVAMPA, M. Feminismos del Sur y ecofeminismos; Fundación Foro Nueva Sociedad; Nueva Sociedad. v. 256, n.4, p.127-131, 2015.

TOLEDO, E. O aumento da violência contra a mulher na pandemia de Covid-19: um problema histórico. Disponível em: http://coc.fiocruz.br/index.php/pt/todas-as-noticias/1781o-aumento-da-violencia-contra-a-mulher-na-pandemia-de-covid-19-um-problemahistorico.html\#.XsPUI2hKjIU

VOGEL, L. Domestic labor revisited. Science \& Society. v. 64, n. 2, p. 151-170, 2000.

WOOD, J. L. N; LEACH, M. WALDMAN, L.; MACGREGOR, H.; FOOKS, A.; JONES, K.; RESTIF, O.; DECHMANN, D.; HAYMAN, D.; BAKER, K. , PEEL, A.; KAMINS, A.; FAHR, J.; NTIAMOABAIDU Y.; SUU-IRE, R; BREIMAN, R. EPSTEIN, J.; FIELD, H.; CUNNINGHAM, A. A framework for the study of zoonotic disease emergence and its drivers: spillover of bat pathogens as a case study. Phil. Trans. R. Soc. B. v. 367, p. 28812892, 2012.

\footnotetext{
${ }^{\text {i }}$ Doutoranda em Educação pelo Programa de Pós Graduação em Educação/PPGEdu da Universidade Federal do Estado do Rio de Janeiro/UNIRIO. Pesquisadora do Grupo de Estudos de Educação Ambiental desde el Sur (GEASur/UNIRIO). Email: agoliva86@gmail.com ORCID: https://orcid.org/0000-0001-9854-8581

ii Professora da Escola de Educação e do Programa de Pós Graduação em Educação/PPGEdu da Universidade Federal do Estado do Rio de Janeiro/UNIRIO. Coordenadora do Grupo de Pesquisa "Infâncias, Tradições Ancestrais e Cultura Ambiental (GiTaKa) e do Núcleo Infâncias, Natureza e Artes/NiNA/UNIRIO. Doutora em Educação pela Pontifícia Universidade Católica do Rio de Janeiro/PUC-Rio. Email: lea.tiriba@gmail.com ORCID: https://orcid.org/0000-0001-9508-5980
} 
iii No Pará, Maranhão, Rio Grande do Sul e Ceará foram publicados decretos incluindo o trabalho doméstico como atividade essencial, em equivalência a bancos e mercados. O que motivou a elaboração de uma campanha contrária a esta decisão, pela Federação Nacional das Trabalhadoras Domésticas (Fenatrad). https://soscorpo.org/campanhanacional-quer-barrar-inclusao-de-servicos-domesticos-de-atividades-essenciais-nos-estados-pressione-agora/

iv Isso porque, este país não conta com um sistema de saúde público e os procedimentos médicos são muito caros. Com isso, as pessoas mais pobres, grande parte delas afrodescendentes, não conseguem fazer os tratamentos para doenças crônicas, muitas delas responsáveis pelo agravamento do quadro dos pacientes infectados pela Covid-19 (SANTOS, 2020).

v Sistema Único de Saúde.

${ }^{\text {vi }}$ Dentre as organizações da campanha estão: CONTAG, Marcha das Mulheres, Articulação Nacional de Agroecologia e muitas outras.

vii Destacamos a luta das mulheres camponesas, no Brasil, em plenos anos 2000 pelo reconhecimento de seus direitos como trabalhadoras rurais e não apenas como ajudantes, como foram consideradas, na maior parte do tempo (SILIPRANDI, 2012).

viii Creches públicas, escolas, assistência social, serviços de saúde e saneamento, etc.

${ }^{\text {ix }}$ Diegues (2001) comenta que, nas populações indígenas esta interconexão com a natureza é mais conhecida. No entanto, outras populações não indígenas, que experienciaram certo isolamento dos ciclos econômicos extrativistas, desde a época da colônia, também desenvolveram modos de vida interdependentes dos ciclos naturais e mantenedores da biodiversidade. Prova disso é que encontramos a maioria das áreas naturais protegidas no Brasil, criadas a partir dos anos 30, em áreas ocupadas anteriormente por populações tradicionais. Áreas ecologicamente bem conservadas pelo modo de vida destes grupos.

x Tomemos como exemplo a luta da ambientalista e defensora dos direitos humanos Berta Cáceres e seus companheiros, em Honduras. As resistências populares contra a instalação de hidroelétricas nas regiões dos rios, tidos como sagrados e fonte de sobrevivência para os camponeses e indígenas de origem lena, trouxeram muitas conquistas, mas também dolorosas derrotas, como o assassinato criminoso de Berta (HOMAND, 2016).

xi Santos (2002) chama a atenção para a existência de diferentes tipos de globalização, considerando-a não como advento recente, mas já presente no colonialismo e no imperialismo. No entanto, reitera a singularidade da "globalização hegemônica" que vivemos hoje, de caráter fortemente neoliberal, cuja tendência principal é a homogeneização e imposição dos modelos de desenvolvimento e consumo anglo-euro-centricos para as realidades locais, em todo mundo.

xii A Articulação dos Povos Indígenas do Brasil (APIB) denunciou que no período de isolamento social, suas comunidades estão enfrentando um aumento nas invasões dos territórios por madeireiros, garimpeiros, missionários e grileiros, além do aumento do assassinato de suas lideranças. http://apib.info/2020/05/01/durantea-pandemia-funai-emite-norma-que-incentiva-invasao-de-terras-indigenas/. As declarações do atual ministro do meio ambiente defenderam que o momento da pandemia representa uma oportunidade para a desregulação da proteção ambiental e possibilidade de deixar "passar a boiada" reforçando os interesses do agronegócio sobre os territórios protegidos. https://brasil.elpais.com/brasil/2020-05-22/salles-ve-oportunidade-com-coronavirus-parapassar-de-boiada-desregulacao-da-protecao-ao-meio-ambiente.html

xiii Nos anos 1970, mulheres de distintas partes do planeta mobilizaram-se para protestar contra a destruição ambiental. O movimento Green Belt do Quênia, e o movimento Chipko na Índia, são os exemplos mais conhecidos. O termo "ecofeminismo" foi cunhado pela escritora francesa Françoise d'Eaubonne, em 1974 .Setores do feminismo radical se articularam à luta ambientalista, formando este movimento (MERCHANT, 1992).

xiv No campo da educação ambiental pode-se definir, segundo Layrargues e Lima (2014) três principais macrotendências: a conservadora, a crítica e a pragmática.

${ }^{x v}$ Caracterizado pela grande concentração de terras, pelo uso intensivo de defensivos químicos e pela disseminação dos transgênicos. 